\title{
Analysis on Application of Traditional Arts and Crafts in Exhibition Design
}

\author{
Zhiang Wang \\ Shanghai University of Engineering Science, Shanghai, China \\ Email: mlbsabc@sina.com
}

How to cite this paper: Wang, Z.A. (2017) Analysis on Application of Traditional Arts and Crafts in Exhibition Design. Open Journal of Social Sciences, 5, 85-89. https://doi.org/10.4236/jss.2017.54008

Received: March 23, 2017

Accepted: April 18, 2017

Published: April 21, 2017

Copyright $\odot 2017$ by author and Scientific Research Publishing Inc. This work is licensed under the Creative Commons Attribution International License (CC BY 4.0).

http://creativecommons.org/licenses/by/4.0/

\begin{abstract}
Traditional arts and crafts are the important form and part of our traditional culture, the artistic form of historic and cultural connotation, also an important direction to carry forward the traditional art culture. In recent years, the development speed of exhibition art accelerated continuously. It highlights the function of traditional arts and crafts elements. The significance and value of traditional arts and crafts in modern industrial design cannot be ignored. This paper analyzes and introduces development and characteristics of traditional Chinese arts and crafts, makes an in-depth analysis on how to apply traditional arts and crafts to modern exhibition design and proposes the significance of applying traditional arts and crafts to exhibition design, in order to provide reference for the development of traditional Chinese arts and crafts and the combination of it and modern process design through exploration of countermeasures in the future.
\end{abstract}

\section{Keywords}

Exhibition, Design, Traditional Arts and Crafts, Application, Countermeasures

\section{Introduction}

Our country has more profound historic and cultural connotation than other countries. In abundant and diversified traditional culture of our country, the traditional Chinese arts and crafts outshine others and influence the historical and cultural development for thousands of years. The traditional arts and crafts derive from the cottage craft in the period of natural economic development, in order to meet the personal needs of producers. At that time, the works of arts and crafts had functions of production and consumption and strong aesthetic value. Therefore, the traditional arts and crafts are not only heritage and valuable wealth left by our ancestors but also an important link in the continuous de- 
velopment of traditional culture [1]. It has become the problem that we must consider in exhibition design and the key influencing the development of exhibition about how to combine traditional arts and crafts with modern industrial development and how to integrate the traditional and classical beauty in modern aesthetic development.

\section{Development and Characteristics of Traditional Chinese Arts and Crafts}

The traditional Chinese arts and crafts are historical, cultural and artistic. So the historical and cultural element with a long history inevitably has a long influence on modern society and directly carries forward the cultural spirit of traditional arts and crafts.

According to the development of traditional Chinese arts and crafts, in the Neolithic Age, people in the Yellow River basin had burnt pottery. In Yuan dynasty, Jingdezhen became the well-know porcelain making center of our country, which show the development of traditional Chinese arts and crafts makes a breakthrough. Except for p orcelain, the noted bronze ware is also an important representative of traditional arts and crafts. It began in about $2000 \mathrm{BC}$ and was in a period of great prosperity in Shang dynasty [2]. The casting technique, production variety and diversified modeling of bronze wares embody high attainment of traditional Chinese arts and crafts. From the perspective of its development and characteristics, arts and crafts show in many aspects. With the continuous social progress, porcelains and bronze wares express the enrichment and improvement of traditional culture and technical forms of our country.

\section{Countermeasures and Methods of Applying Traditional Arts and Crafts in Exhibition Design}

\subsection{Pay Attention to the Inheritance of Traditional Arts and Crafts and the Provision of Development Policies}

According to the development of traditional arts and crafts and exhibition design, in order to effectively apply traditional arts and crafts to exhibition design, we must provide policy support and space for inheritance and development of it. At present, there is no legal system in our country to restrict the traditional arts and crafts. Many people hold ambiguous attitudes the intellectual property protection of traditional arts and crafts. In order to pursue high economic interest, the exhibition industry takes works of traditional arts and crafts as props for imitation [3]. Traditional arts and crafts fail to exert their value. The inheritance and development of traditional arts and crafts and the restriction and improvement in policy protection are keys to effectively apply it to exhibition design and the fundamental to improve the level of exhibition design.

\subsection{Combine Traditional Arts and Crafts with Modern Culture and Realize Innovation}

As a unique artistic form, in order to develop in modern society and show its 
significance and value, the traditional Chinese arts and crafts must strictly flow the development law. At the meantime, we need to innovate in and improve the traditional craft materials. For example, in modern exhibition, we should carry out technological improvement of new materials, integrate and apply new materials in craftworks with modern style. It needs to apply new crafts or integrate new flower color in exhibitions like porcelains, so that it can enrich the connotation of artistic works and realize the integration of culture. Besides, we can combine traditional handicraft with modern machine technology to integrate traditional arts and crafts in modern exhibition design.

\subsection{Make Application According to Characteristics of Traditional Arts and Crafts}

1) Color

Color is an important element and an obvious characteristic in traditional arts and crafts. Rich color matching and unique modeling contribute to the earliest arts and crafts works of our country. These works existed in the Old Stone Age. In subsequent development, porcelains, bronze wares and silks manifest the characteristic of arts and crafts works in color and show people's pursuit for the artistic forms of traditional fine arts culture [4] [5]. One of the characteristics of traditional Chinese arts and crafts works is that the color is strong and bright and the color saturation is high. It is also typical style and technique of traditional arts and crafts works in color application. Furthermore, the embodiment of emotional elements in traditional arts and crafts depends on color. Undoubtedly, in modern exhibition design, the application of color is a crucial method. The application of bright and strong color of traditional arts and crafts to exhibition can attract visitors promptly. The high color saturation can stimulate visitors' optic nerve and make them analyze the elements, understand the color characteristics and accept the traditional arts and crafts works.

2) Modeling

Many contents in traditional Chinese arts and crafts works like famous stoneware, enamel, gold and silver articles and sculptures embody modeling elements. From the perspective of art, these works have big value and reflect different levels of cultural development at different stages. It shows the level of social civilization and people's pursuit of ideal society as well as emotional expression. The significances of modeling and color in traditional arts and crafts works are similar. Modeling elements include classic hollow-carved design, pattern design and lattice design. They become popular in modern exhibition design and embody vital significance and value in the development of traditional Chinese arts and crafts. In modern exhibition, the exhibition stands and showcases integrate artistic style and characteristics of traditional arts and crafts works. People like to integrate hollow-carved design in exhibition, which make the exhibition retro [6]. The integration of retro and modern fashion shows new artistic form, successfully attracting visitors. At present, the exhibition contents include architecture, aesthetics, science and technology, materials and lighting. The products full of 
modern color can be supported by modeling elements of traditional aesthetics. It certainly will appeal to visitors, improve their recognition degree and guarantee the significance and function of exhibition.

3) Artistic conception

Artistic conception is a common concept in traditional arts and crafts works as well as a typical aesthetic element. It needs to integrate emotional, cultural and historical elements to form new artistic form. Artistic conception has typical characteristics with high quality and taste in modern exhibition. The traditional arts and crafts works form unique style and lasting appeal because of the profound historical and cultural background. According to the development status of modern exhibition design, it is of vital importance to apply elements of traditional arts and crafts improve the taste and artistic conception of design. The introduction of artistic conception elements can endow the exhibition with strong historical and cultural lingering charm. For example, the traditional ceramic lines of baby blue and light white can be applied to wall design of exhibition to create classical beauty [7].

\section{Necessity of Applying Traditional Arts and Crafts in Exhibition Design}

\subsection{Enrich the Cultural Connotation of Exhibition Design}

In reality, because of the absence of corresponding cultural deposits, the traditional arts and crafts works fail to embody its value. In view of this, in future exhibition design, we should endow traditional arts and crafts works with new cultural and times connotation, in order to effectively enrich the practical significance of exhibition. In exhibition of traditional embroidery, we can divide it according to different areas like Suzhou embroidery, Sichuan embroidery, Hunan embroidery and Guangdong embroidery, to make it easier for visitors to know about embroideries in different areas. Meanwhile, from the perspective of visual observation, we can effectively present characteristics of different embroideries and combine it with regional culture, so that the cultural connotation of them is enriched. For example, the exhibition of Sichuan embroidery enables visitors to observe the difference of it and other embroideries. In Sichuan embroidery, people use silk thread to embroider decorative patterns on silk cloth or other fabrics and they are bright-colored through red and green colors. In the exhibition of it, we can arrange the showcase and display wall according to lines of Sichuan embroidery. They echo each other at a distance. It can highlight the delicacy and beauty of Sichuan embroidery and plays a vital role in improving the artistic value of traditional arts and crafts works.

\subsection{It Is the Inheritance and Development of Traditional Arts and Crafts}

According to the development of modern exhibition and traditional arts and crafts, the traditional arts and crafts works applied in modern society have strong artistic and aesthetic values and social influence. It is crucial to carry for- 
ward and popularize the traditional culture and elements of arts and crafts like traditional ceramics, bronze, enamel and silk. Color, modeling, artistic conception and dissimilation of traditional cultural concept show abundant and diversified traditional art elements. Moreover, we can effectively present the characteristics of arts and crafts works in different areas through modern science and technology to improve the ornamental and aesthetic value of exhibits. It can effectively embody themes and contents of exhibition and achieve the ultimate purpose of exhibition [8].

\section{Conclusion}

With thousands of years of history and civilization, our country has profound cultural deposits. The development of traditional culture and art has more and more influence on modern society and modern art design. Traditional arts and crafts are treasures of traditional Chinese culture and art. Meanwhile, with diversified art elements and modes, it positively promotes and influences modern exhibition design. In future development, it is necessary to continuously explore the cultural connotation and characteristics of elements in traditional Chinese arts and crafts, the development tendency of exhibition design industry at the present stage and effectively combine with them, in order to improve the artistic value of elements in arts and crafts and more extensively apply it in modern exhibition design.

\section{References}

[1] Zhang, Y.H. (2016) Analysis on the Teaching Value of Traditional Arts and Crafts Resources from the Perspective of Art and Design Teaching. Beauty and Times, 11, 116-118.

[2] Wu, W.T. (2015) Expression of Traditional Arts and Crafts in Exhibition Design. Hundred Schools in Arts, S1, 128-130.

[3] Meng, M.M. (2014) Analysis on the Influence of Art Element in Traditional Arts and Crafts on Modern Exhibition Design. Art Science and Technology, 6, 413.

[4] Liu, S.W. (2014) Analysis on the Relationship between Traditional Arts and Crafts and Modern Design. Technology Innovation, 5, 283.

[5] Wang, Y.X. (2013) Influence of Traditional Arts and Crafts on Modern Exhibition Design. Art and Design (Theory), 4, 70-72.

[6] Xu, P.J. (2008) Summary on Seminar of "Protection and Development of Traditional Chinese Arts and Crafts. Art Observation, 7, 22-24.

[7] Wang, Y.Y. (2003) Research on the Modernization of Inheritance of Traditional Arts and Crafts in Beijing City. Journal of Capital Normal University (Social Science Edition), S1, 111-116.

[8] Tang, K.M. (2000) Art Language Is the Life of Traditional Arts and Crafts. Zhejiang Arts and Crafts, 1, 7-8. 
Submit or recommend next manuscript to SCIRP and we will provide best service for you:

Accepting pre-submission inquiries through Email, Facebook, LinkedIn, Twitter, etc. A wide selection of journals (inclusive of 9 subjects, more than 200 journals)

Providing 24-hour high-quality service

User-friendly online submission system

Fair and swift peer-review system

Efficient typesetting and proofreading procedure

Display of the result of downloads and visits, as well as the number of cited articles Maximum dissemination of your research work

Submit your manuscript at: http://papersubmission.scirp.org/

Or contact jss@scirp.org 